\title{
Never neglect the atmospheric pressure effect on a brain with a skull defect
}

This article was published in the following Dove Press journal:

International Medical Case Reports Journal

26 March 2014

Number of times this article has been viewed

\author{
Hsiao-Yue Wee' \\ Jinn-Rung Kuo ${ }^{1,2}$ \\ 'Department of Neurosurgery, \\ Chi-Mei Medical Center, ${ }^{2}$ Department \\ of Biotechnology, Southern Taiwan \\ University of Science and Technology, \\ Tainan, Taiwan
}

\begin{abstract}
Herein, we report an unusual case of a patient who presented with a severe, sinking skin flap after a decompressive craniectomy and ventriculoperitoneal shunt surgery due to a traumatic brain injury. After cranioplasty, the patient's neurological deficiency improved and was confirmed by transcranial Doppler sonography. In addition to discussing the pathogenesis of the sinking skin flap, we emphasize the importance of cranioplasty for neurological improvement and remind the surgeon to "never neglect the atmospheric pressure effect on a brain with a skull defect".
\end{abstract}

Keywords: traumatic brain injury, decompressive craniectomy, hydrocephalus, cranioplasty

\section{Introduction}

Decompressive craniectomy is a common practice and considered to be a life-saving procedure in patients with severe traumatic brain injury. ${ }^{1}$ Post-traumatic hydrocephalus is a complication needing a ventriculoperitoneal shunt to divert cerebrospinal fluid. ${ }^{2}$ A sinking scalp flap occasionally develops after decompressive craniectomy and could be aggravated by a ventriculoperitoneal shunt. ${ }^{3-5}$ In such cases, the purpose of cranioplasty at the craniectomy site is to eliminate atmospheric pressure, restore the cerebrospinal fluid, and improve neurological status. ${ }^{6-10}$ Here we present an unusual case of a severe sinking scalp flap after decompressive craniectomy and ventriculoperitoneal shunt.

\section{Case report}

A 65-year-old male patient was transferred to our hospital with a large, right-sided skull defect and severe scalp depression. He had suffered a traumatic brain injury 5 months earlier and undergone decompressive craniectomy and removal of an intracranial hemorrhage at that time. Hydrocephalus developed one month after the operation and he received a ventriculoperitoneal shunt. However, his level of consciousness progressively deteriorated thereafter. On neurological examination, he was drowsy with a Glasgow Coma Scale score of E1 V1M4 and profound left hemiplegia. A computed tomography (CT) brain scan revealed marked concavity of the brain at the craniectomy site associated with midline shift to the left (Figure 1). Transcranial Doppler sonography (MultiDop $^{\circledR}$ X2, DWL; Elektronische Systeme GmbH, Schlotheim, Germany) was unable to detect the wave pattern of the blood flow in the middle cerebral artery of the concave brain. The impression was of sinking skin flap syndrome, so cranioplasty with bone cement was performed. Postoperatively, the patient was treated with hydration and bed
Correspondence: Jinn-Rung Kuo Department of Neurosurgery, Chi-Mei Medical Center, 90I Chung Hwa Road, Yung Kang City, Tainan 7I0, Taiwan

Tel 88662812811

Fax 88662828928

Email kuojinnrung@gmail.com 


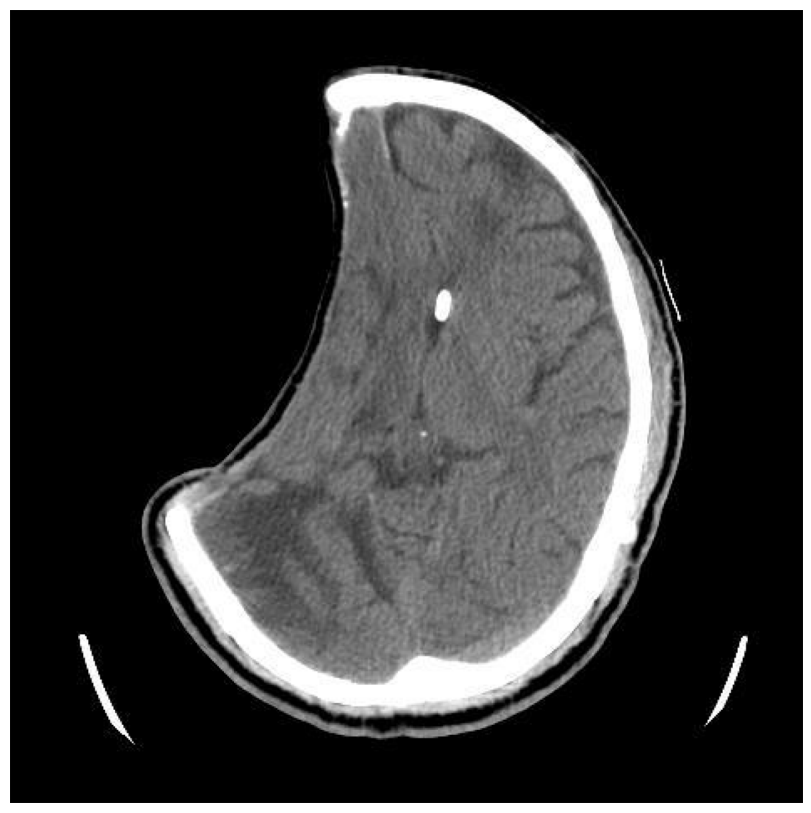

Figure I Computed tomography scan of the axial brain showing sinking at the craniectomy site with extensive midline shift and the proximal tube of the ventricular peritoneal shunt.

rest for 3 days. Four days after his cranioplasty, follow-up CT images showed reversal of the midline shift with no significant complications in the underlying brain (Figure 2). Follow-up transcranial Doppler revealed a mean velocity of $30 \mathrm{~cm}$ per second in the right middle cerebral artery. After the surgery, the patient's mentality gradually improved to an

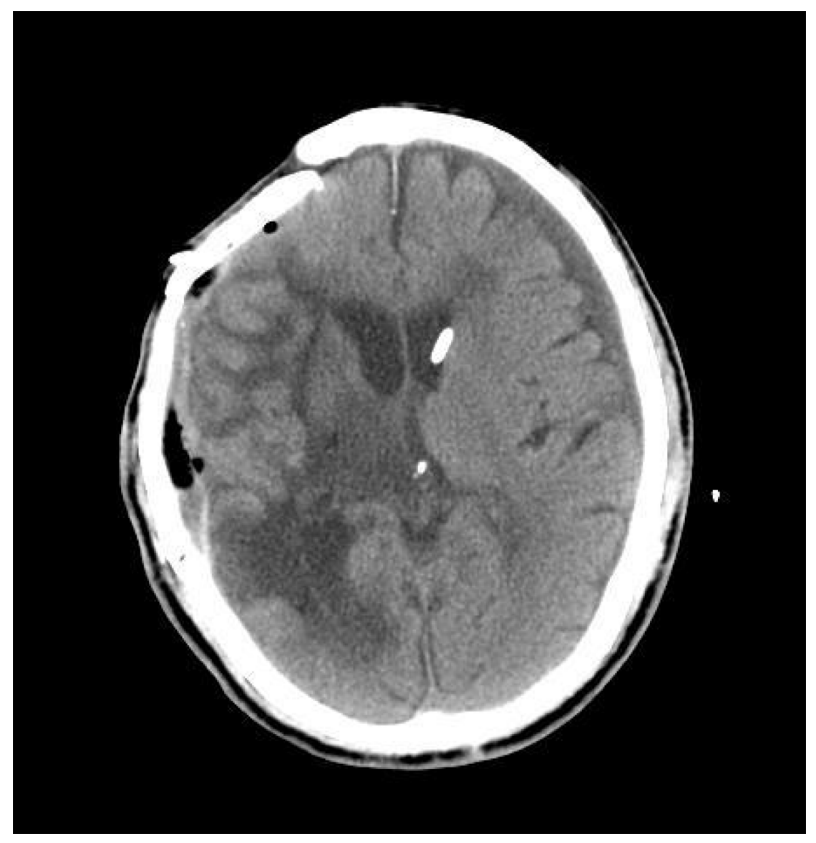

Figure 2 Computed tomography scan showing reversal of the sunken brain contour and the midline shift after an autologous cranioplasty repair of the skull defect. alert state and he was discharged with a Glasgow Coma Scale score of E34V1M5-6 one month after cranioplasty.

\section{Discussion}

Decompressive craniectomy is widely used as a life-saving measure to treat intracranial hypertension following traumatic brain injury. ${ }^{1}$ However, it has been identified as a risk factor for changes in cerebrospinal fluid and development of posttraumatic hydrocephalus, for which a ventriculoperitoneal shunt may be necessary for diversion of cerebrospinal fluid. $^{2}$

Mean atmospheric pressure is $1,033 \mathrm{~cm} \mathrm{H}_{2} \mathrm{O}$ of water and equivalent to $14.7 \mathrm{psi}^{2} \mathrm{~A}$ ventriculoperitoneal shunt for hydrocephalus in patients with a skull defect may lead to excessive sinking at the craniectomy site as a result of the atmospheric pressure gradient, which could be aggravated by diversion of cerebrospinal fluid and change in position, especially when there is post-traumatic brain parenchymal atrophy or loss, as in our case. ${ }^{3,4}$ Thus, the goal of treatment in a patient with a sinking skin flap is to eliminate atmospheric pressure at the craniectomy site via cranioplasty.

However, performing a cranioplasty on a patient with a severe concave scalp flap at the craniectomy site does increase the risks of accumulation of fluid and formation of hematoma. ${ }^{5}$ To relieve the pressure gradient between the atmosphere and the intracranial space and to reverse the scalp depression and midline shift, temporary occlusion of the shunt device ${ }^{5}$ or reprogramming of the ventriculoperitoneal shunt to a higher valve pressure before cranioplasty ${ }^{6}$ have been recommended. However, our patient underwent cranioplasty without temporary occlusion or shunt reprogramming, but rather hydration and postoperative bedrest for 3 days. Follow-up CT of the brain showed good brain expansion with no formation of hematoma. Nevertheless, we recommend early combined cranioplasty and programmable shunts for patients with skull bone defects to avoid sunken skin in accordance with the suggestion of Carvi et al. ${ }^{7}$

In our case, the possible reason for decreasing cerebral blood flow in a brain with a skull defect can be explained as impairment of brain autoregulation (due to insult of previous traumatic brain injury) and the local compression effect of atmospheric pressure. Several important principles have been described with regard to intracranial dynamics in relation to the conventional physiological regulatory mechanism of cerebral blood flow, including pressure autoregulation, regulation of $\mathrm{CO}_{2}$, and regulation of metabolism. ${ }^{8}$ In an experiment by Schaller et al, cats that underwent hemicraniectomy showed decreased cerebral blood flow in normal brain tissue that 
lasted for at least one day. ${ }^{9}$ We thought it might be related to a local compression effect by atmospheric pressure; however, the normal brain without traumatic injury is able to restore cerebral blood flow in a few days. Therefore, cranioplasty is able to improve neurological status in patients with a skull bone defect. ${ }^{10}$ It reduces the local compression effect of atmospheric pressure, thereby improving brain autoregulation and enhancing cerebral hemodynamic status. ${ }^{9-10}$ This result is consistent with our previous study about neurological improvement after cranioplasty, increasing velocity of cerebral blood flow can be seen on transcranial Doppler. ${ }^{11}$

We report here an unusual case of a patient who presented with a severe sinking skin flap after decompressive craniectomy and ventriculoperitoneal shunt due to traumatic brain injury. This case underscores the importance of cranioplasty and reminds surgeons to "never neglect the atmospheric pressure effect on a brain with a skull defect".

\section{Disclosure}

The authors report no conflicts of interest in this work.

\section{References}

1. Coplin WM, Cullen NK, Policherla PN, et al. Safety and feasibility of craniectomy with duraplasty as the initial surgical intervention for severe traumatic injury. J Trauma. 2001;50(6):1050-1059.
2. Mazzini L, Campini R, Angelino E, Rognone F, Pastore I, Oliveri G. Posttraumatic hydrocephalus: a clinical, neuroradiologic, and neuropsychologic assessment of long-term outcome. Arch Phys Med Rehabil. 2003;84(11):1637-1641.

3. Yamamura A, Sato M, Meguro K, Nakamura T, Uemura K, Makino H. [Cranioplasty following decompressive craniectomy. Analysis of 300 cases]. No Shinkei Geka. 1997;5(4):345-353. Japanese.

4. Kelley GR, Johnson PL. Sinking brain syndrome: craniotomy can precipitate brainstem herniation in CSF hypovolemia. Neurology. 2004;62(1):157.

5. Liao CC, Kao MC. Cranioplasty for patients with severe depressed skull bone defect after cerebrospinal fluid shunting. J Clin Neurosci. 2002;9:553-555.

6. Han PY, Kim JH, Kang HI, Kim JS. Syndrome of the sinking skin-flap secondary to the ventriculoperitoneal shunt after craniectomy. $J$ Korean Neurosurg Soc. 2008;43(1):51-53.

7. Carvi Y, Nievas MN, Hollerhage HG. Early combined cranioplasty and programmable shunt in patients with skull bone defects and CSF-circulation disorders. Neurol Res. 2006;28(2):139-144.

8. Schaller B, Graf R. Different compartments of intracranial pressure and its relationship to cerebral blood flow. J Trauma. 2005;59(6): 1521-1531.

9. Schaller B, Graf R, Sanada Y, Rosner G, Wienhard K, Heiss WD Hemodynamic and metabolic effects of decompressive hemicraniectomy in normal brain. An experimental PET-study in cats. Brain Res. 2003;982(1):31-37.

10. Segal DH, Oppenheim JS, Murovic JA. Neurosurgical recovery after cranioplasty. Neurosurgery. 1994;34(4):729-731.

11. Kuo JR, Wang CC, Chio CC, Cheng TJ. Neurological improvement after cranioplasty - analysis by transcranial Foppler ultrasonography. J Clin Neurosci. 2004;11(5):486-489.
International Medical Case Reports Journal

\section{Publish your work in this journal}

The International Medical Case Reports Journal is an international, peer-reviewed open-access journal publishing original case reports from all medical specialties. Previously unpublished medical posters are also accepted relating to any area of clinical or preclinical science. Submissions should not normally exceed 2,000 words or

\section{Dovepress}

4 published pages including figures, diagrams and references. The manuscript management system is completely online and includes a very quick and fair peer-review system, which is all easy to use. Visit http://www.dovepress.com/testimonials.php to read real quotes from published authors. 